\title{
Clinicopathologic characteristics of ovarian clear cell carcinoma in the background of endometrioma: a surveillance strategy for an early detection of malignant transformation in patients with asymptomatic endometrioma
}

\author{
Joo-Hyuk Son ${ }^{1,2}$, Seokyoung Yoon ${ }^{2}$, Seokyung Kim², Tae-Wook Kong ${ }^{1,2}$, Jiheum Paek ${ }^{1,2}$, Suk-Joon Chang ${ }^{1,2}$, \\ Hee-Sug Ryu ${ }^{1,2}$
}

${ }^{1}$ Division of Gynecologic Oncology, ${ }^{2}$ Department of Obstetrics and Gynecology, Ajou University School of Medicine, Suwon, Korea

\section{Objective}

This study aimed to analyze the clinical features of clear cell carcinoma in relation to endometriosis and to determine an appropriate surveillance strategy for the early detection of malignant transformation of endometrioma in asymptomatic patients.

\section{Methods}

We retrospectively reviewed the clinicopathologic data of 50 patients with ovarian clear cell carcinoma. Clinicopathologic characteristics, treatment outcomes, and the association between endometriosis and the risk of malignant transformation were analyzed.

\section{Results}

Ten $(20 \%)$ patients had been diagnosed with endometrioma before the diagnosis of clear cell carcinoma. The median period from the diagnosis of endometrioma to clear cell carcinoma diagnosis was 50 months (range, 12-213 months). After complete staging surgery, histological confirmation of endometriosis was possible in $35(70 \%)$ patients. Of the 50 patients, $39(78 \%)$ had not undergone any gynecologic surveillance until the onset of symptoms, at which time many of them presented with a rapidly growing pelvic mass (median $10 \mathrm{~cm}$, range $4.6-25 \mathrm{~cm}$ ). With the exception of 2 patients, all cancer diagnoses were made when the patients were in their late thirties, and median tumor size was found to increase along with age. Asymptomatic patients $(n=11)$ who had regular gynecologic examinations were found to have a relatively smaller tumor size, lesser extent of tumor spread, and lower recurrence rate $(P=0.011,0.283$, and 0.064 , respectively). The presence of endometriosis was not related to the prognosis.

\section{Conclusion}

Considering the duration of malignant transformation and the timing of cancer diagnosis, active surveillance might be considered from the age of the mid-thirties, with at least a 1-year interval, in patients with asymptomatic endometrioma.

Keywords: Endometrioma; Neoplastic cell transformation; Epithelial ovarian cancer; Prognosis

\section{Introduction}

Endometriosis is a common disease entity affecting around $10 \%$ of reproductive-age women [1]. It has a wide variety of clinical consequences ranging from benign lesions to malignant transformation [2-4]. In a pooled analysis of casecontrol studies, endometriosis was found to be significantly correlated with increased risk of epithelial ovarian cancer,
Received: 2017.12.06. Revised: 2018.07.03. Accepted: 2018.07.17. Corresponding author: Suk-Joon Chang Divison of Gynecologic Oncology, Department of Obstetrics and Gynecology, Ajou University School of Medicine, 164 World cupro, Yeongtong-gu, Suwon 16499, Korea

E-mail: drchang@ajou.ac.kr

https://orcid.org/0000-0002-0558-0038

Articles published in Obstet Gynecol Sci are open-access, distributed under the terms of the Creative Commons Attribution Non-Commercial License (http://creativecommons. org/licenses/by-nc/3.0/) which permits unrestricted non-commercial use, distribution, and reproduction in any medium, provided the original work is properly cited.

Copyright $\odot 2019$ Korean Society of Obstetrics and Gynecology 


\section{Obstetrics \& Gynecology Science}

Vol. 62, No. 1, 2019

especially clear cell adenocarcinoma [5]. In addition, a recent study has provided significant evidence of an association between endometriosis-related genetic variation and ovarian cancer risk, especially in those with clear cell histotypes [6]. In spite of these risks, there are still debates and disagreements as to the optimal treatment and follow-up strategies for patients with endometriosis. Although several guidelines have been developed to provide information on the diagnosis, treatment, and prevention of endometriosis, there is still a lack of evidence regarding follow-up intervals and the timing of surgical intervention especially in patients with asymptomatic endometriosis [7-10]. Surgical treatment of endometriomas may confer the benefit of histological confirmation along with a protective effect against later development of ovarian cancer $[7,11]$. On the other hand, universal surgical resection of endometriomas may cause operative risk and decreased ovarian reserve $[12,13]$. Previous studies suggested that the risk of malignant transformation of endometriosis was approximately $1 \%$ for premenopausal women and $1-2.5 \%$ for postmenopausal women $[14,15]$. In a Japanese prospective study, malignant transformation was reported in about $46(0.72 \%)$ of 6,398 patients with endometriosis after a median follow-up period of 12.8 years [16].

Despite the low potential for malignant transformation of endometriosis and the relatively long latent period, studies investigating the management strategies for endometriosis, especially in asymptomatic patients, are urgently needed. The aim of this study was to examine the treatment outcomes of clear cell carcinoma of the ovary in relation to endometriosis and to determine an appropriate management strategy for asymptomatic patients with endometrioma.

\section{Materials and methods}

A retrospective review of medical records was performed in patients with clear cell carcinoma of the ovary who were diagnosed and treated between 2001 and 2017 at Ajou University Hospital, Suwon, Korea. A total of 50 consecutive patients with ovarian clear cell carcinoma were identified. All the patients were evaluated with Siemens Acuson S2000 Ultrasound system (Siemens Healthcare, Ultrasound Business Unit, Mountain View, CA, USA) and computed tomographic (CT) scans to inspect the characteristics of the adnexal masses before surgery. Forty-nine patients underwent complete staging surgery, while one patient refused to undergo surgery.

After the surgery, patients received adjuvant systemic chemotherapy with paclitaxel $\left(175 \mathrm{mg} / \mathrm{m}^{2}\right)$ plus 3 to 6 cycles of carboplatin (area under the curve [AUC] of 6). Clinicopathologic characteristics including age at diagnosis, parity, body mass index (BMI), initial symptoms, maximum tumor diameter, and ovarian involvement (laterality) were analyzed. Treatment outcomes including the type of treatment, International Federation of Gynecology and Obstetrics (FIGO) stage, status of residual disease, and disease recurrences were analyzed. Recurrence was defined based on Gynecologic Cancer Intergroup criteria after evaluation using the Response Evaluation Criteria in Solid Tumors guidelines [17]. If a patient was diagnosed with endometrioma prior to surgery, the associations between endometriosis and clear cell carcinoma were analyzed, including a previous diagnosis of endometriosis and the latent period until the diagnosis of clear cell carcinoma. Statistical analysis was performed using IBM SPSS Statistics for windows (version 20.0, IBM Corp., Armonk, NY, USA). Risk factors were compared according to recurrence status using the Mann-Whitney $U$ test for continuous data and Pearson's $\chi^{2}$ test or Fisher's exact test for categorical data. $P$-values less than 0.05 were considered statistically significant.

\section{Results}

During the study period, a total of 533 patients with epithelial ovarian cancer (EOC) were identified. Clear cell carcinoma of the ovary comprised $9.3 \%$ (50/533) of the EOC. Median age at diagnosis was 49.5 (range, 25-75) years; 42 patients $(42 / 50,82 \%)$ were older than 40 years at the time of diagnosis, and only 2 patients were younger than 37 years in this patient cohort. The median tumor size increased with increasing patient age (Fig. 1). Most patients' symptoms were related to the mass effect of the tumor. Frequent symptoms included palpable mass (32\%), abdominal distention (20\%), and abdominal pain (20\%). Only 11 (22\%) patients were diagnosed during gynecologic evaluation and did not have any symptoms. Of the 50 patients, 40 patients (80\%) had a unilateral ovarian tumor with a size greater than $8 \mathrm{~cm}$. Ten (20\%) patients had been diagnosed with endometrioma before the diagnosis of clear cell carcinoma. The initial diagnosis of en- 


\section{Obstetrics \& Gynecology Science}

Joo-Hyuk Son, et al. Surveillance strategy of endometrioma

dometrioma was made by ultrasonography. Nine of the patients self-reported the previous diagnosis of endometrioma in a local clinic, and 1 patient was diagnosed in our institution. However, not all patients had follow-up visits after the initial diagnosis of endometrioma made by ultrasonography. Histologic confirmation of endometriosis was possible in 35 (70\%) patients after complete staging surgery. The median time period from the diagnosis of endometriosis to clear cell carcinoma was 50 (range, 12-213) months in the 10 patients (Table 1).

The median tumor size in the patients without and with an endometriosis background was $9.7 \mathrm{~cm}$ (range, 5-20) and $10.5 \mathrm{~cm}$ (range, 4.6-25), respectively. Presence of endometriosis on pathology was not associated with tumor size or patient age ( $P=0.519$ and 0.451 , respectively), nor was it related to the prognosis (FIGO stage, $P=0.747$; disease recurrence, $P=0.672$ ) (Table 2 ). Interestingly, among patients who had been diagnosed via routine gynecologic examination, only 1 patient experienced disease recurrence $(1 / 11,6.7 \%)$. Asymptomatic patients $(n=11)$ who had regular gynecological examinations were found to have a relatively smaller tumor size, lesser extent of tumor spread, and lower recurrence rate $(P=0.011,0.283$, and 0.064 , respectively) (Table 3 ).

Thirty-eight patients underwent primary debulking surgery, 3 had neoadjuvant chemotherapy with interval debulking surgery due to a comorbid condition or extensive disease

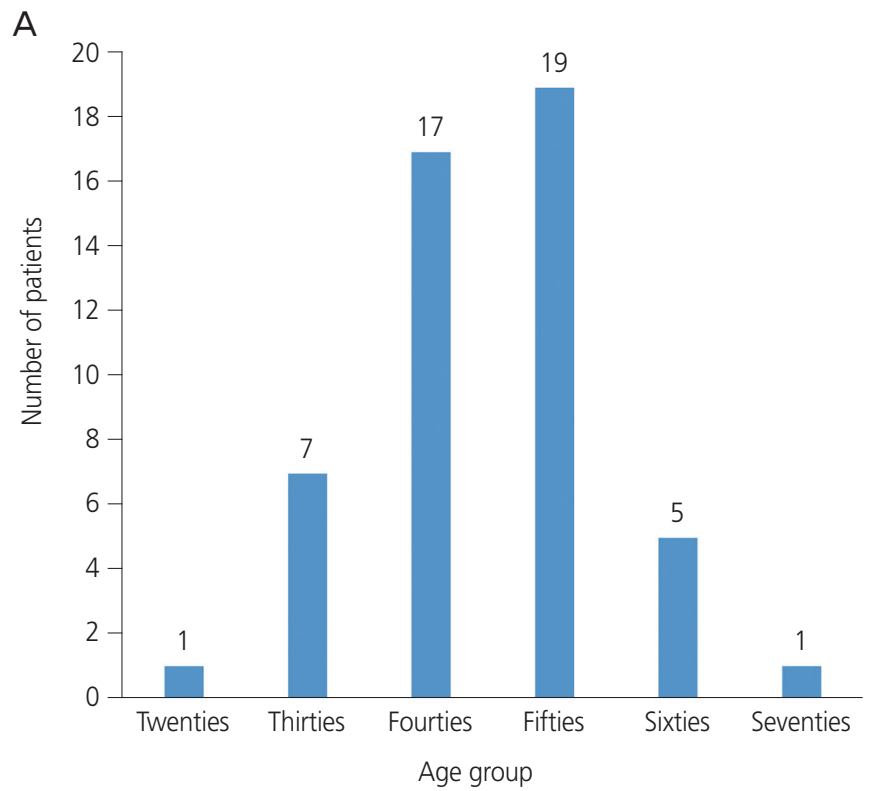

burden, and 8 had re-staging surgery after unilateral ovarian cystectomy or unilateral salpingo-oophorectomy. Of the 50 patients, 35 (70\%) were diagnosed with FIGO stage I or II disease. Four patients (8\%) were found to have concurrent thromboembolic disease during the follow-up period. Fifteen patients experienced disease recurrence (Table 4). Among the various clinicopathologic factors, FIGO stage and the status of residual disease were the only significant factors affecting disease recurrence. A previous history of endometriosis was not a significant factor for recurrence $(P=0.654)$ (Table 5).

\section{Discussion}

According to this study, nearly three-quarters of the clear cell carcinoma cases were confirmed in the background of endometriosis. Most patients were diagnosed during their late thirties or forties with a median of 4 years until malignant change. Yet, asymptomatic patients who were diagnosed during regular gynecologic evaluations were more likely to present with a smaller tumor size and early FIGO stage. More importantly, they experienced a low rate of recurrent disease.

Considering the risk of malignant potential in endometriosis, appropriate follow-up strategies are indispensable. Previous epidemiological and molecular studies have indicated that endometriosis is the most plausible precursor of

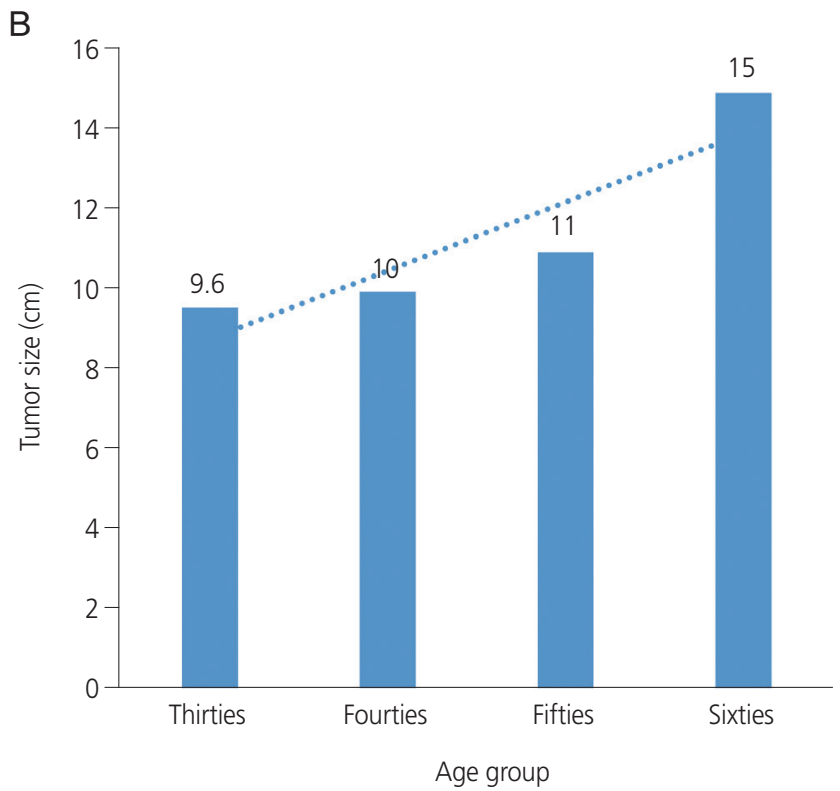

Fig. 1. (A) Number of patients diagnosed with clear cell carcinoma according to the age group. (B) Median tumor size according to the age at diagnosis of clear cell carcinoma. 


\section{Obstetrics \& Gynecology Science}

Vol. 62, No. 1, 2019

Table 1. Clinicopathologic characteristics of patients with ovarian clear cell carcinoma $(n=50)$

\begin{tabular}{lc}
\hline Characteristics & Values \\
\hline Age at diagnosis & $49(25-75)$ \\
Parity & 2 (0-4) \\
BMI (kg/m²) & $22.2(17.9-36.1)$ \\
Menopause patients & $17(34)$ \\
Age of menopause & $48(46-55)$ \\
Initial symptoms and median tumor size (cm) & \\
Palpable mass & $16(32), 11.5(9-25)$ \\
Incidental diagnosis during follow-up & $11(22), 8.5(4.6-10.8)$ \\
Abdominal distension & $10(20), 11.4(5-16)$ \\
Abdominal pain & $10(20), 10.0(7.3-15)$ \\
Urinary symptom & $2(4), 17(15-19)$ \\
Vaginal discharge & $1(2), 5$ \\
Maximum diameter of tumor by pelvic ultrasound (cm) & $10(20)$ \\
$4-8$ & $25(50)$ \\
$8-12$ & $15(30)$ \\
$>12$ & $10(4.6-25)$ \\
Median diameter (cm) & \\
Ovarian involvement & $40(80)$ \\
Unilateral & $17(46)$ \\
Right & $23(34)$ \\
Left & $10(20)$ \\
Bilateral & \\
Biagnosis of endometrioma or endometriosis & $10 / 50(20)$ \\
\hline After staging surgery for clear cell carcinoma (based on histologic diagnosis) & $35 / 50(70)$ \\
\hline Latent period (month) & $50(12-213)$ \\
\hline Data
\end{tabular}

Data are presented as median (range) or number (\%).

$\mathrm{BMI}$, body mass index.

Table 2. Characteristics of the patients with or without endometriosis background

\begin{tabular}{lccc}
\hline Characteristics & $\begin{array}{c}\text { Patients with endometriosis } \\
\text { background }(\mathbf{n}=\mathbf{3 5})\end{array}$ & $\begin{array}{c}\text { Patients without endometriosis } \\
\text { background (n=15) }\end{array}$ & P-value \\
\hline Tumor size $(\mathrm{cm})$ & $9.7(5-20)$ & $10.5(4.6-25)$ & 0.519 \\
Age at diagnosis & $47(33-60)$ & $50(25-65)$ & 0.451 \\
FIGO stage & & & 0.747 \\
I or II & $25(71.4)$ & $10(66.7)$ & 0.572 \\
III or IV & $10(28.6)$ & $5(33.3)$ & $4(26.6)$ \\
Recurrence event & $11(31.4)$ & &
\end{tabular}

Data are presented as median (range) or number (\%).

FIGO, International Federation of Gynecology and Obstetrics. 


\section{Obstetrics \& Gynecology Science}

Joo-Hyuk Son, et al. Surveillance strategy of endometrioma

Table 3. Clinical stages and recurrence events during the follow-up periods in patients with ovarian clear cell carcinoma

\begin{tabular}{lccc}
\hline Characteristics & $\begin{array}{c}\text { Incidental diagnosis during gynecologic } \\
\text { follow-up }(\mathbf{n}=\mathbf{1 1})\end{array}$ & Symptomatic diagnosis $(\mathbf{n}=\mathbf{3 9})$ & $\boldsymbol{P}$-value \\
\hline Tumor size & $9.6(4.6-10.8)$ & $11(5-25)$ & 0.011 \\
FIGO stage & $9(9 / 11,81.8)$ & $26(26 / 39,66.7)$ & 0.283 \\
I, II & $2(2 / 11,18.2)$ & $13(13 / 39,33.3)$ & \\
III, IV & $1(1 / 11,9.1)$ & $14(14 / 39,35.8)$ & 0.064 \\
Recurrence event & & & \\
\hline
\end{tabular}

Data are presented as median (range) or number (\%).

FIGO, International Federation of Gynecology and Obstetrics.

Table 4. Treatment outcomes

\begin{tabular}{lc}
\hline Characteristics & Values \\
\hline Operation type & $38(76)$ \\
PDS & $3(6)$ \\
IDS & $8(16)$ \\
Re-staging operation & $1(2)$ \\
Biopsy only & \\
FIGO stage & $30(60)$ \\
I & $5(10)$ \\
II & $12(24)$ \\
III & $3(6)$ \\
IV & $1(2)$ \\
Synchronous endometrial cancer & \\
Concurrent thromboembolic disease & $1(2)$ \\
DVT & $3(6)$ \\
PTE & \\
Recurrence event by stage (\%) & $2(6.7)$ \\
I & $2(40)$ \\
II & $9(75)$ \\
III & $2(67)$ \\
IV & $15(30)$ \\
Total & $34.0(2-164)$ \\
\hline Total follow up period (month) &
\end{tabular}

Data are presented as median (range) or number (\%).

PDS, primary debulking surgery; IDS, interval debulking surgery; FIGO, International Federation of Gynecology and Obstetrics; DVT, deep vein thrombosis; PTE, pulmonary thromboembolism.

ovarian clear cell carcinoma [5,6,18-20]. In a meta-analysis of 13 case-control studies including 7,911 women with EOC, women with a self-reported history of endometriosis had three times the risk of clear cell carcinoma (odds ratio [OR], $3.05 ; 95 \%$ confidence interval $[C \mathrm{Cl}, 2.43-3.84 ; P<0.0001)$ and double the risk of endometrioid $(\mathrm{OR}, 2.04 ; 95 \% \mathrm{Cl}$,
1.67-2.48; $P<0.0001)$ and low-grade serous carcinoma (OR, $2.11,95 \% \mathrm{Cl}, 1.39-3.20)$ [5]. In previous studies, the mechanisms of malignant transformation were suggested to be related to the activation of oncogenic KRAS and PISK pathways and inactivation of tumor suppressor genes PTEN and ARID1A $[19,20]$. Menopause status has also been indicated as a potential risk factor [14]. In premenopausal woman, the risk of malignant transformation of endometriosis has been estimated at around 1 percent [15]. However, there have been no age-specific guidelines for the timing of active surveillance in asymptomatic patients. Current guidelines recommend that endometriomas be removed only if they have an atypical appearance on imaging studies or other concerning features such as enlarged size in asymptomatic patients, though no information as to the timing or interval of surveillance has been provided [21].

In this patient cohort, many patients were asymptomatic until the median tumor size was about $10 \mathrm{~cm}$. In addition, $80 \%$ of the patients did not receive any surveillance until the onset of symptoms, and many of them characteristically presented with a rapidly growing pelvic mass in a background of endometriosis. In a Japanese study of 33 patients with clear cell carcinoma, tumor size was found to have doubled in the 6 months prior to the diagnosis of malignant transformation in 30 patients. These patients had been followed for at least 2 years after the diagnosis of ovarian endometrioma and continued to be followed after the identification of malignant transformation [22]. In the current study, asymptomatic patients who had regular gynecologic examinations were found to have a relatively smaller tumor size with less tumor spreading. In light of the median duration (50 months; range, 12-123 months) of malignant transformation and the age of cancer incidence, surveillance should be started from the age of the mid-thirties, with at least 1-year interval sur- 


\title{
Obstetrics \& Gynecology Science
}

\author{
Vol. 62, No. 1, 2019
}

Table 5. Risk factors for ovarian clear cell carcinoma recurrence

\begin{tabular}{|c|c|c|c|}
\hline Characteristics & No Recurrence $(n=35)$ & Recurrence $(n=15)$ & $P$-value \\
\hline Age & 48.2 & 50.0 & 0.726 \\
\hline Parity & 1.8 & 1.4 & 0.402 \\
\hline BMl & 22.8 & 23.1 & 0.426 \\
\hline Menopause status & $12(34.3)$ & $5(33.3)$ & 0.608 \\
\hline Maximum diameter & 10.8 & 12.14 & 0.451 \\
\hline Bilateral ovarian involvement & $5(14.3)$ & $5(33.3)$ & 0.125 \\
\hline Operation type & & & 0.617 \\
\hline PDS & $27(77.1)$ & $11(73.3)$ & \\
\hline IDS & $2(5.7)$ & $1(6.7)$ & \\
\hline Restaging & $6(17.1)$ & $2(13.3)$ & \\
\hline USO (n=5) & 3 & 2 & \\
\hline UOC (n=3) & 3 & 0 & \\
\hline No gross residual disease & $35(100)$ & $11(73.3)$ & 0.006 \\
\hline FIGO stage & & & 0.001 \\
\hline । & $28(80)$ & $2(13.3)$ & \\
\hline$\|$ & $3(8.6)$ & $2(13.3)$ & \\
\hline III & $3(8.6)$ & $9(60.0)$ & \\
\hline IV & $1(2.9)$ & $2(13.3)$ & \\
\hline Concurrent thromboembolic event & $3(8.6)$ & $1(6.7)$ & 0.702 \\
\hline Previous endometriosis diagnosis & $8(22.9)$ & $2(13.3)$ & 0.654 \\
\hline
\end{tabular}

Data are presented as number (\%).

BMI, body mass index; PDS, primary debulking surgery; IDS, interval debulking surgery; USO, unilateral salpingo-oophoretomy; UOC, unilateral ovarian cystectomy; FIGO, International Federation of Gynecology and Obstetrics.

veillance in asymptomatic patients with endometriosis. Owing to the rapid growth characteristics of clear cell carcinoma, patients should be also informed as to the risk of cancer and the necessity of regular gynecologic surveillance despite a lack of symptoms. If the tumor size increases during regular follow-up, surgical treatment should be considered, since ovarian clear cell carcinoma has been known to be chemoresistant with an extremely low chemo-response rate $[23,24]$.

The current study has some limitations. First, the retrospective nature of the study might have inevitably led to a patient or treatment selection bias. Second, since the most patients with endometriosis were diagnosed at a local clinic, we could not confirm the effectiveness of various multimodal screening tools including CA-125 and sonography. Third, other than age, the risk factors for malignant transformation were not confirmed in this study. Further large studies focusing on the risk factors and screening tools for malignant transformation are necessary. Despite these limitations, the current study has proposed a surveillance strategy for asymptomatic patients with endometriosis. Despite the overall low incidence of ovarian clear cell carcinoma, the current study had a relatively long follow-up period in a single institution. In addition, all patients were treated with the same quality of medical and surgical treatment.

In summary, early detection of malignant transformation during gynecologic evaluation and surgical intervention are directly associated with oncologic prognosis in asymptomatic endometriosis patients. For the timely detection of malignant transformation of ovarian endometrioma, at least 1-year interval surveillance and counseling should be provided, commencing in the patients' mid-thirties.

\section{Conflict of Interest}

No potential conflict of interest relevant to this article was 


\section{Obstetrics \& Gynecology Science}

Joo-Hyuk Son, et al. Surveillance strategy of endometrioma

reported.

\section{Ethical approval}

This retrospective study was approved by Institutional Review Board of Ajou University Hospital (AJIRB-MED-MDB-18-438).

\section{Patient consent}

Patient consent was waived by the Institutional Review Board since, in this study, a retrospective chart review was utilized as a method of data collection.

\section{References}

1. Gupta D, Hull ML, Fraser I, Miller L, Bossuyt PM, Johnson $N$, et al. Endometrial biomarkers for the non-invasive diagnosis of endometriosis. Cochrane Database Syst Rev 2016;(4):CD012165.

2. Santoro L, D'Onofrio F, Flore R, Gasbarrini A, Santoliquido $A$. Endometriosis and atherosclerosis: what we already know and what we have yet to discover. Am J Obstet Gynecol 2015;213:326-31.

3. Kvaskoff M, Mu F, Terry KL, Harris HR, Poole EM, Farland $L$, et al. Endometriosis: a high-risk population for major chronic diseases? Hum Reprod Update 2015;21:500-16.

4. Ferreira AL, Bessa MM, Drezett J, de Abreu LC. Quality of life of the woman carrier of endometriosis: systematized review. Reprod Clim 2016;31:48-54.

5. Pearce CL, Templeman C, Rossing MA, Lee A, Near AM, Webb PM, et al. Association between endometriosis and risk of histological subtypes of ovarian cancer: a pooled analysis of case-control studies. Lancet Oncol 2012;13:385-94.

6. Lee AW, Templeman C, Stram DA, Beesley J, Tyrer J, Berchuck $A$, et al. Evidence of a genetic link between endometriosis and ovarian cancer. Fertil Steril 2016;105:3543.e1.

7. Schleedoorn MJ, Nelen WL, Dunselman GA, Vermeulen $\mathrm{N}$; EndoKey Group. Selection of key recommendations for the management of women with endometriosis by an international panel of patients and professionals.
Hum Reprod 2016;31:1208-18.

8. Johnson NP, Hummelshoj L; World Endometriosis Society Montpellier Consortium, Abrao MS, Adamson GD, Allaire $C$, et al. Consensus on current management of endometriosis. Hum Reprod 2013;28:1552-68.

9. American College of Obstetricians and Gynecologists. ACOG updates guideline on diagnosis and treatment of endometriosis. Am Fam Physician 2011;83:84-5.

10. Hwang H, Chung YJ, Lee SR, Park HT, Song JY, Kim H, et al. Clinical evaluation and management of endometriosis: guideline for Korean patients from Korean Society of Endometriosis. Obstet Gynecol Sci 2018;61:553-64.

11. Melin AS, Lundholm C, Malki N, Swahn ML, Sparèn $P$, Bergqvist A. Hormonal and surgical treatments for endometriosis and risk of epithelial ovarian cancer. Acta Obstet Gynecol Scand 2013;92:546-54.

12. Uncu G, Kasapoglu I, Ozerkan K, Seyhan A, Oral Yilmaztepe A, Ata B. Prospective assessment of the impact of endometriomas and their removal on ovarian reserve and determinants of the rate of decline in ovarian reserve. Hum Reprod 2013;28:2140-5.

13. Biacchiardi CP, Piane LD, Camanni M, Deltetto F, Delpiano EM, Marchino GL, et al. Laparoscopic stripping of endometriomas negatively affects ovarian follicular reserve even if performed by experienced surgeons. Reprod Biomed Online 2011;23:740-6.

14. Van Gorp T, Amant F, Neven P, Vergote I, Moerman P. Endometriosis and the development of malignant tumours of the pelvis. A review of literature. Best Pract Res Clin Obstet Gynaecol 2004;18:349-71.

15. Oxholm D, Knudsen UB, Kryger-Baggesen N, Ravn P. Postmenopausal endometriosis. Acta Obstet Gynecol Scand 2007;86:1158-64.

16. Kobayashi H, Sumimoto K, Moniwa N, Imai M, Takakura $K$, Kuromaki $T$, et al. Risk of developing ovarian cancer among women with ovarian endometrioma: a cohort study in Shizuoka, Japan. Int J Gynecol Cancer 2007; 17:37-43.

17. Eisenhauer EA, Therasse P, Bogaerts J, Schwartz LH, Sargent $D$, Ford $R$, et al. New response evaluation criteria in solid tumours: revised RECIST guideline (version 1.1). Eur J Cancer 2009;45:228-47.

18. Prowse AH, Manek S, Varma R, Liu J, Godwin AK, Maher ER, et al. Molecular genetic evidence that endometriosis is a precursor of ovarian cancer. Int J Cancer 


\section{Obstetrics \& Gynecology Science}

Vol. 62, No. 1, 2019

2006;119:556-62.

19. Munksgaard PS, Blaakaer J. The association between endometriosis and ovarian cancer: a review of histological, genetic and molecular alterations. Gynecol Oncol 2012;124:164-9.

20. Grandi G, Toss A, Cortesi L, Botticelli L, Volpe A, Cagnacci $A$. The association between endometriomas and ovarian cancer: preventive effect of inhibiting ovulation and menstruation during reproductive life. BioMed Res Int 2015;2015:751571.

21. Dunselman GA, Vermeulen N, Becker C, Calhaz-Jorge C, D'Hooghe T, De Bie B, et al. ESHRE guideline: management of women with endometriosis. Hum Reprod
2014;29:400-12.

22. Taniguchi F, Harada T, Kobayashi H, Hayashi K, Momoeda M, Terakawa N. Clinical characteristics of patients in Japan with ovarian cancer presumably arising from ovarian endometrioma. Gynecol Obstet Invest 2014;77:10410.

23. Takano M, Tsuda H, Sugiyama T. Clear cell carcinoma of the ovary: is there a role of histology-specific treatment? J Exp Clin Cancer Res 2012;31:53.

24. Itamochi H, Kigawa J, Terakawa N. Mechanisms of chemoresistance and poor prognosis in ovarian clear cell carcinoma. Cancer Sci 2008;99:653-8. 